\title{
Role of limited access dressing in achieving improved aesthetic results during resurfacing of wounds
}

\author{
Pramod Kumar \\ Department of Plastic surgery, King Fahad Central Hospital, Jazan 82666, Saudi Arabia.
}

Correspondence to: Dr. Pramod Kumar, Department of Plastic Surgery, King Fahad Central Hospital, Jazan 82666, Saudi Arabia. E-mail: pkumar86@hotmail.com

\begin{abstract}
How to cite this article: Kumar P. Role of limited access dressing in achieving improved aesthetic results during resurfacing of wounds. Plast Aesthet Res 2020;7:27. http://dx.doi.org/10.20517/2347-9264.2020.07
\end{abstract}

Received: 11 Jan 2020 First Decision: 14 Apr 2020 Revised: 18 Apr 2020 Accepted: 6 May 2020 Published: 27 May 2020

Science Editor: Raúl González-García Copy Editor: Jing-Wen Zhang Production Editor: Tian Zhang

\begin{abstract}
With refinement and better understanding of Plastic Surgery, there is increasing expectation of aesthetic outcomes after resurfacing of wounds. The major problems in resurfacing procedures are tissue bulk, donor site issues, excessive scarring and distal edema due to damaged lymphatics and veins after flap harvest from adjacent areas in the extremities. Ultra-conservative debridement simplifies reconstruction by reducing the need for flaps and improves the chances of skin graft take through limited access dressing, which can improve the final aesthetic result following reconstruction. In this paper, we describe three representative cases treated under limited access dressing.
\end{abstract}

Keywords: Aesthetic reconstruction, limited access dressing

\section{INTRODUCTION}

If reconstructive surgery restores a defect to a normal looking appearance, aesthetic surgery then surpasses normal. Aesthetic surgery is fascinating because it improves the appearance and makes it pleasing to the observer's eye. After resurfacing procedures, commonly observed problems include a bulky reconstructed part $^{[1,2]}$, scarring and/or defects over the donor and recipient sites, and distal edema in the affected extremities. Reconstructive surgeons have achieved reasonable aesthetic results in reconstruction by utilizing super-thin flaps, reducing donor site scarring by harvesting small islanded flaps, avoiding skin grafting by using rotational/Limberg flaps etc. Hence, in recent years the emphasis has switched towards improving the appearance, texture and better color match in reconstruction. 
Limited access dressing (LAD) $)^{[3,4]}$ is a combination of moist wound healing and negative pressure dressing. Being a dressing technique, it has its own limitations in improving aesthetic appearance. LAD helps in aesthetic reconstruction by simplifying reconstruction with minimal donor area problems and reducing complications due to infection, scarring etc. This is achieved in the following ways:

\section{Ultra conservative debridement}

LAD delivers ultraconservative debridement to conserve viable tissue maximally. It does so through autolytic debridement by tissue enzymes and mechanical debridement by negative pressure and LAD wash. Due to the leech effect, it is possible to keep the wound slough for longer periods with reduced or no risk of SIRS/sepsis. During this waiting period, the living cells proliferate and tissue enzymes separate the attachment of slough to the living tissues. Hence, under LAD, all living tissue is preserved while dead tissue becomes separated. In contrast, when surgery is performed without LAD, much live tissue is removed and depending on the area operated on, if bones or tendons are exposed, reconstruction becomes more difficult with relatively more scarring and poorer aesthetic results.

Debridement and LAD: LAD is applied after thorough mechanical wash and surgical removal of dead tissue. After about 1 week (the actual time required is determined by the appearance of soft and relatively loose slough), if deemed necessary, the wound is debrided again. During debridement, slough is removed easily with minimal blood loss. In cases with compound, comminuted fractures, bone pieces should be preserved, as much as possible, to increase the chances of survival while the wound undergoes LAD.

\section{Minimal scarring}

It has been claimed that occlusive dressings promote rapid wound healing by preventing dehydration and scab formation, facilitating debridement, minimizing the chances of inflammation and infection, reducing pain, increasing the rate of epithelialization, and thus, diminishing scarring.

\section{Less complications after major reconstruction}

After flap cover, intermittent pressure reduces the chances of hematoma formation and venous drainage is improved, thereby reducing the chances of flap failure. It also reduces the chances of infection and inflammation, which in turn, reduces scarring.

\section{Simpler reconstructive procedure}

When treated under LAD, majority of cases can avoid complex reconstruction and split thickness skin grafting (SSG) is usually sufficient. Also, skin graft take is $95 \%-100 \%$ and this helps to reduce the chances of a bulky reconstruction and outcome.

\section{Minimal donor deformity}

As the majority of cases can be covered by SSGs, the expected donor area deformity is thus minimal when compared to flaps. Treatment of the donor area under LAD further reduces the chances of donor site complications.

\section{Less chance of distal edema}

In lower extremity reconstruction, when more than half the circumference is damaged or avulsed and only the flap donor area is intact, further disruption of lymphatics and veins in the flap donor site, if distally based flaps are used, may lead to pedal edema distally. The use of SSGs instead of flaps after LAD reduces or avoids further disruption of the drainage system, which reduces the risk of developing such edema.

\section{Avoiding amputation/major amputation/limb salvage}

On several occasions, it has been possible to avoid limb amputation by using LAD. If aesthetic outcome is the only concern, avoiding major amputation would be an aesthetic gain. 
Table 1. Advantages and disadvantages of limited access dressing in achieving aesthetic results

\begin{tabular}{|c|c|}
\hline Advantages $^{[3-7]}$ & Disadvantages $^{[3]}$ \\
\hline $\begin{array}{l}\text { 1. Ultraconservative debridement } \\
\text { 2. Minimal scarring } \\
\text { 3. Reduces flap failure, wound inflammation and infection } \\
\text { 4. Simpler reconstructive procedure required (graft vs. flap) } \\
\text { 5. Minimal donor site deformity } \\
\text { 6. Reduces chances of distal lymphedema } \\
\text { 7. Increases chances of limb salvage }\end{array}$ & $\begin{array}{l}\text { 1. More time required for treatment if not assisted by surgery } \\
\text { 2. Malodor of occlusive dressing requires limited access dressing wash } \\
\text { 3. Risk of pressure necrosis, especially in ischemic limbs } \\
\text { 4. Hemorrhage }\end{array}$ \\
\hline
\end{tabular}

\section{Disadvantages}

Time taken

Preparation of the wound bed through LAD is faster than other dressing methods, especially if combined with surgical treatment. In cases of gangrene, if there was no surgical debridement, the wound may take $1-1$ and $1 / 2$ months.

\section{Odor}

The malodor of occlusive dressings is usually taken care of by LAD wash and change of soaked dressings at the site of inadequate sealing with leaks.

Pressure necrosis

Tight bandaging at the site where the tube emerges between the skin surface and the LAD bag, or a tight LAD bag may lead to pressure necrosis of the wound. Our improved LAD design has been effective in preventing such complications.

\section{Hemorrhage}

The chances of hemorrhage can be reduced by achieving complete hemostasis prior to application of $\mathrm{LAD}$, adjusting negative pressure, and placing the suction tubing in the folds of plastic, similar to that of a mesentery.

The advantages and disadvantages of LAD are summarized in Table 1.

\section{CASE REPORT}

\section{Case 1}

This is a case of a brachial artery injury in an 18 year old boy that was reconstructed in the emergent setting with a Gortex implant by the vascular surgeon. He underwent LAD immediately after repair [Figure 1]. After 20 days of LAD, the implant was covered by granulation tissue from adjacent muscle and soft tissue. On day 28 , wound resurfacing was achieved by SSG and the patient was discharged on day 38 with $100 \%$ graft take. At 5 months' follow-up, there were no issues with the SSG.

\section{Case 2}

A 26 year old female was referred from General Surgery for wound coverage following debridement for necrotizing fascitis with exposure of the lateral aspect of the leg, knee, and lateral side of the thigh with exposed biceps femoris tendon [Figure 2]. The proximal part of the wound was closed primarily and the rest were treated under LAD. 12 days later, the patient underwent SSG under LAD. After another 10 days, the LAD was removed with $100 \%$ graft take and the patient was discharged. At 6 months' follow up, the skin graft was aesthetically acceptable and the affected limb did not develop distal pedal edema.

\section{Case 3}

A 32 year old male was admitted with trauma to the right knee following a road traffic accident. Examination revealed a $7 \mathrm{~cm} \times 4 \mathrm{~cm}$ wound over the extensor aspect of the knee joint with exposure of the lower half of 

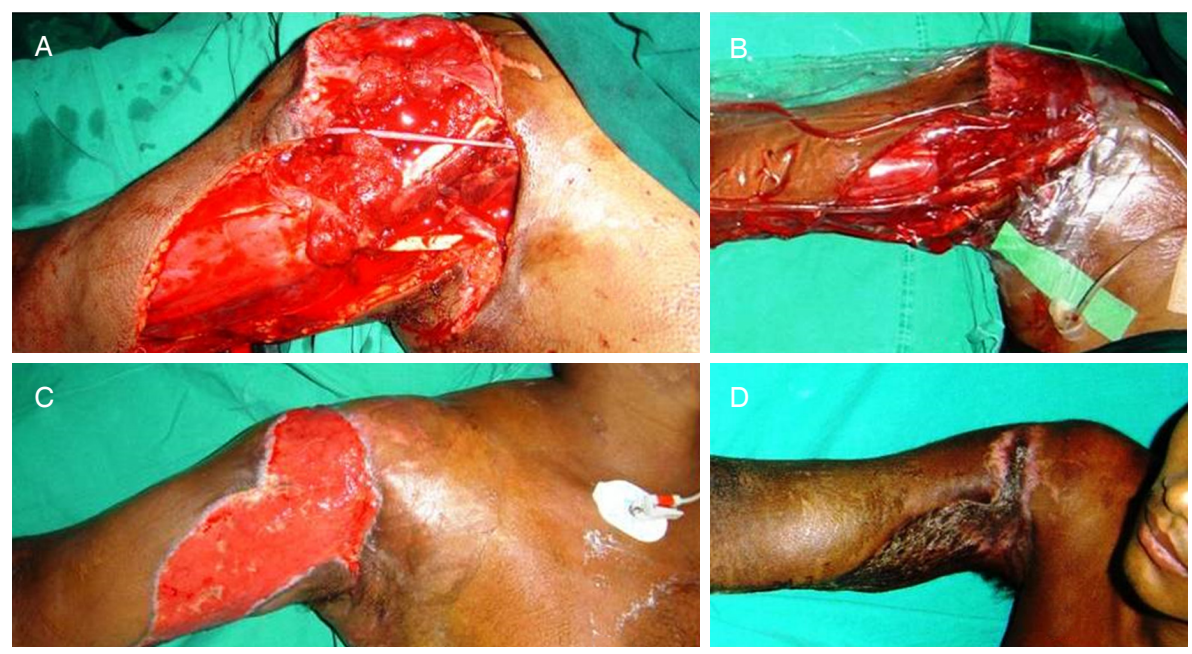

Figure 1. Photographs of case 1 showing: A: exposed Gortex vascular implant; B: limited access dressing covering the wound; C: granulation covering implant after 20 days; D: 3 months after resurfacing by skin graft
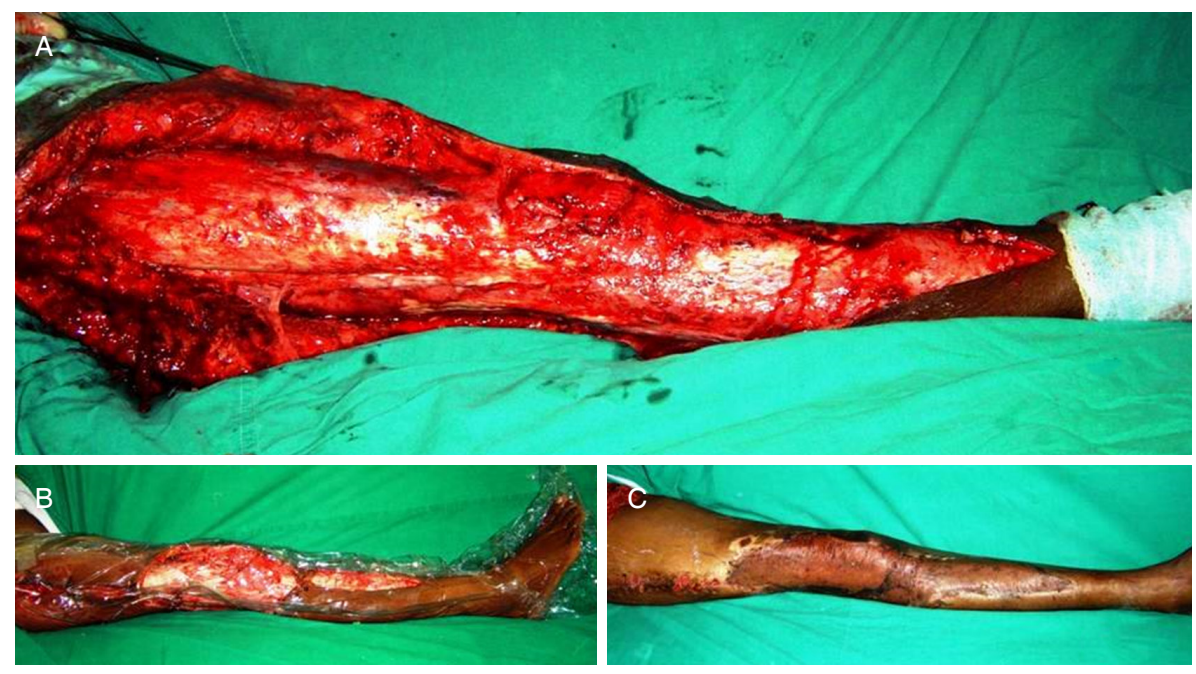

Figure 2. Photographs of case 2 showing: A: extensive wound following debridement for necrotizing fascitis; B: wound preparation under limited access dressing; $\mathrm{C}$ : final result after resurfacing without development of distal edema

the patella, upper part of the patellar ligament, and subpatellar fat pad [Figure 3]. After thorough cleaning and minimal wound debridement, the defect was partially closed with sutures as complete closure was not possible, due to insertion of a tube drain and tubular LAD along with application of a posterior plaster of Paris slab. The LAD was changed after 10 days and final wound closure was achieved under slight tension. After 20 days, the patient was discharged with linear healing of the wound at the suture site [Figure 3C]. After 1 month, the patient was advised for physiotherapy. At 3 months' follow-up, the wound had healed well with mild hypertrophy and full range of motion of the knee.

\section{DISCUSSION}

\section{Case 1}

Major options available in this case were pedicled flaps including the latissimus dorsi flap, subscapular flap and lateral thoracic flap ${ }^{[8]}$. These flaps provide relative bulk to the recipient site compared to a SSG and come with donor site related problems such as compromised function and scarring. By using LAD, it was possible to achieve granulation over the Gortex implant and later, definitive coverage with a SSG in 28 days 

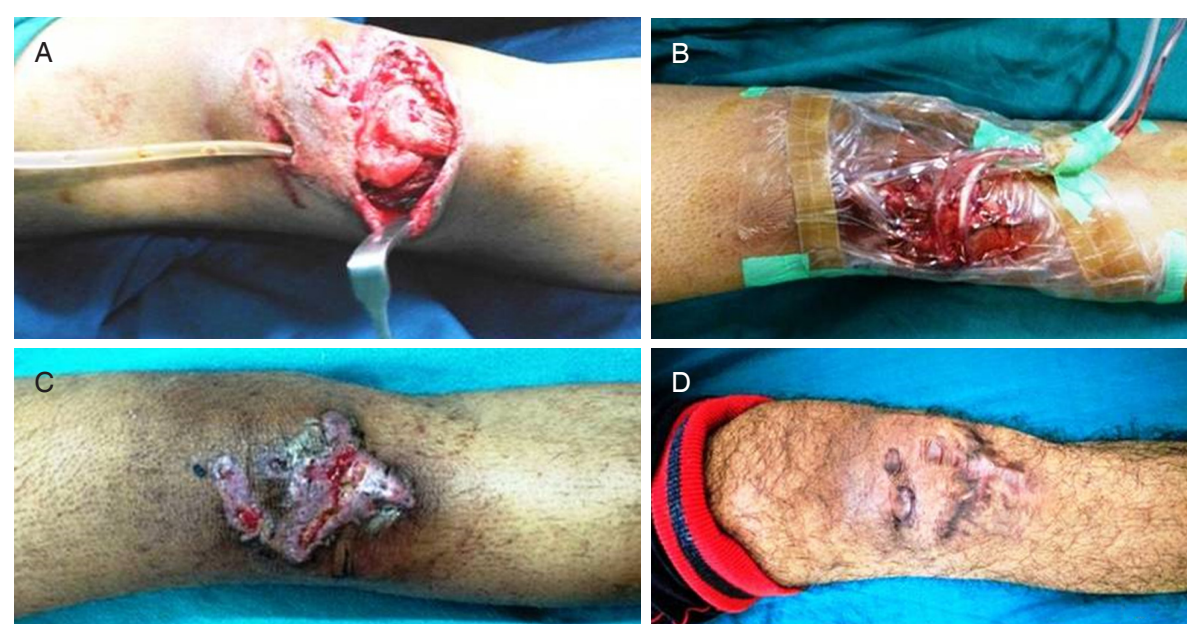

Figure 3. Photographs of case 3 showing: A: post-traumatic defect over knee; B: limited access dressing applied over the wound (see text for detail); C: 20 days post-limited access dressing result; D: result after 3 months

with a better and less bulky aesthetic result. At centers with microsurgical capabilities, free flap surgery can be expected to provide a better cosmetic result in a shorter time. But in the absence of such facilities and expertise, $\mathrm{LAD}$ is more reliable and a better alternative for a better aesthetic result. Also, the patient required physiotherapy in the post-operative period. There was minimal wound contracture after 6 months and no corrective surgery was required.

\section{Case 2}

In this case, ultraconservative debridement ${ }^{[4]}$ under LAD avoided further tissue loss and intermittent negative pressure with moist healing promoted granulation tissue formation over the wound bed and exposed tendon. Generally, skin flaps from the remaining half of the circumference of the affected limb may cause damage to the remaining lymphatics and result in intractable lymphedema. Successful resurfacing with SSG provided an acceptable result without distal edema and limb contracture.

\section{Case 3}

Common flaps available for coverage of the exposed patella and patellar tendon are the medial gastronemius, extended myocutaneous or fasciocutaneous flap ${ }^{[9]}$. All these flaps cause significant donor site defects, which could easily be avoided by using LAD. In the present case, the reconstruction result was not bulky and did not have any donor defect or distal edema. The exposed patella and patellar tendon were covered by granulation tissue under the moist environment of LAD. Approximating sutures were applied to bring the skin edges together and the gap in between epithelialized.

The above cases suggest that LAD may be a useful tool in achieving a higher level of aesthetic outcomes in the resurfacing of extensive or difficult to treat wounds by avoiding bulky flaps, significant donor site defects, and distal edema due to compromised drainage from harvesting large regional flaps.

\section{DECLARATIONS}

\section{Authors' contributions}

The author contributed solely to the article.

\section{Availability of data and materials}

Not applicable. 


\section{Financial support and sponsorship}

None.

\section{Conflicts of interest}

The author declared that there are no conflicts of interest.

\section{Ethical approval and consent to participate}

Informed consent to participate in the study was obtained from the patients.

\section{Consent for publication}

A written informed consent for publication was obtained from the patients.

\section{Copyright}

(C) The Author(s) 2020.

\section{REFERENCES}

1. Kim TG, Choi MK. Secondary contouring of flaps. Arch Plast Surg 2018;45:319-24.

2. Wei FC, Mardini S. Flap and reconstructive surgery. 2nd ed. Amsterdam: Elsevier; 2019.

3. Kumar P. Exploiting potency of negative pressure in wound dressing using limited access dressing and suction-assisted dressing. Indian $\mathrm{J}$ Plast Surg 2012;45:302-15.

4. Kumar P. Advanced wound care using limited access dressing (LAD). JSWCR 2015;8:1-3

5. Kumar P. Diabetic foot salvage by limited access dressing (LAD). J Diabetes Metab 2014;5:365.

6. Kumar P. Limited access dressing and wound infection. Plast Aesthet Res 2015;2:237-8.

7. Kumar P. Limited Access Dressing. Wounds 2008;20:49-59.

8. Management of axillary defect of hidradenitis suppurativa using keystone design islanded perforator flap--a simple and durable option. The Free Library. 2018 Akshantala Enterprises Private Limited 10 Jan. 2020. Available from: https://www.thefreelibrary.com/Journal + of + Evolution+of+Medical+and+Dental+Sciences/2018/January/8-p54797 [Last accessed on 15 May 2020]

9. Gravvanis A, Kyriakopoulos A, Kateros K, Tsoutsos D. Flap reconstruction of the knee: a review of current concepts and a proposed algorithm. World J Orthop 2014;5:603-13. 